\title{
A Review: Effect of Friction Stir Welding on Microstructure and Mechanical Properties of Magnesium Alloys
}

\author{
Yajie Li, Fengming Qin, Cuirong Liu and Zhisheng $\mathbf{W u}$ * \\ School of Materials Science and Engineering, Taiyuan University of Science and Technology, \\ Taiyuan 030024, China; liyajie1207@126.com (Y.L.); qinfengming1014@126.com (F.Q.); lcr@tyust.edu.cn (C.L.) \\ * Correspondence: zswu@tyust.edu.cn; Tel.: +86-0351-216-1126
}

Received: 13 October 2017; Accepted: 22 November 2017; Published: 25 November 2017

\begin{abstract}
Friction stir welding (FSW) is well recognized as a very practical technology for joining magnesium alloys. Although, a large amount of progress have been made on the FSW of magnesium alloys, it should be emphasized that many challenges still remain in joining magnesium using FSW. In this article, we briefly review the background of friction stir welding of magnesium alloys, and then focus on the effects of the friction stir welding on the macrostructure, microstructure evolution, texture distribution, and the mechanical properties of the welding joints. The macro-defects in welds and their relationship to the welding parameters such as welding speed, rotation speed, and axial force were also discussed. The review concluded with some suggested methods improvement and future challenges related to FSW of magnesium alloys. The purpose of the present review paper is to fully understand the relationships between the microstructure and the properties, and then establish a global, state-of-the-art FSW of magnesium alloys.
\end{abstract}

Keywords: friction stir welding; magnesium alloy; macrostructure; microstructure; mechanical properties

\section{Introduction}

As light weight engineering materials, magnesium alloys are widely used in the automotive, aerospace, and ship building industries due to their highly specific strength, ductility, and low density [1,2]. Nevertheless, because of the limited number of slip systems associated with a hexagonal, close-packed crystal structure, magnesium alloys have poor workability [3]. Thus, a considerable amount of research has focused on the joining technologies of magnesium alloys like arc welding [4], resistance welding [5], electron beam welding [6], and laser welding [7]. However, the defects, e.g., hot cracking, residual stress, partial melting zone, and porosity generated by conventional fusion welding process [8], significantly deteriorate joints properties, which hinders the wide range of applications of magnesium alloys in the aerospace field and the automobile industry. Hence, joining magnesium alloys by means of solid-state processes appears to be the best solution to these problems. Friction stir welding (FSW) was developed by The Welding Institute (TWI) of United Kingdom as a solid-state joining technique, and it has many advantages when welding magnesium alloys [9-13].

A limited number of slip systems available in magnesium alloys, as well as their propensity for mechanical twinning, may strongly promote their microstructure evolution. It has been found that the FSW of magnesium alloys can cause pronounced grain refinement [14], which improves their comprehensive properties. The formation of the equiaxed grain structure in FSWed welds is commonly referred as recrystallization and is a prominent effect of grain refinement in nugget zone (NZ). However, strong local texture commonly occurs in FSWed magnesium alloy welds and significantly deteriorates the tensile mechanical property [15]. Therefore, it is important to reveal the relationship between 
microstructure evolution and the mechanical properties of FSWed Mg alloys. Recently, a great deal of research has been done on the FSW of magnesium alloys all over the world, and several review papers on FSW have been published. Maz systematically reviewed friction stir processing technology [11]. Avettand-Fènoël et al. [16] discussed the FSW of metal matrix composites in detail. Salih et al. [17] gave an overview of the FSW of aluminium matrix composites. Thomas et al. [18], Rai and Bhadeshia [19], and Zhang et al. [20] comprehensively reviewed the FSW tools of aluminium alloys. However, there are few systematic review papers about the friction stir welding of magnesium alloys. In order to provide an in-depth understanding of the FSW of magnesium alloys and further improve their joint properties, this review paper first gives a brief description of friction stir welding technology (Section 2). Then, this paper mainly focuses on several critical questions such as an analysis of macrostructure, microstructure, and the mechanical properties of FSW joints in magnesium alloys (Sections 3-6). Finally, the conclusions, including future challenges and research directions, are discussed.

\section{Brief Review of Friction Stir Welding (FSW)}

Friction stir welding has been in development for 25 years and was originally intended to be used in the joining of aluminium alloys. By now, the reach of FSW has extended to a variety of materials including steels and all kinds of light metals; it is possible that it will replace conventional fusion welding in the future. As FSW is capable of joining magnesium alloys without melting, and thus the metallurgical problems associated with it can be eliminated, good quality weld can be obtained [21].

FSW Equipment is relatively simple and mainly consists of a rotating shoulder and a pin, as shown in Figure 1. The tool is defined as having an Advancing Side (AS) and a Retreating Side (RS), respectively. The former is the region in which the welding speed vector and the rotational speed are collinear (the directions between the two sides are opposite). During the welding process, the non-consumable rotating pin is inserted into the faying surface of the sheets with a proper tilt angle and then moved in the direction of the welding line. By means of a combination of tool rotation and linear motion, weld metal undergoes strong plastic deformation and complex mixing around the rotation axis [22]. Yang [23] and his colleagues have reported that three distinct regions, i.e., the flow transition zone, the stir zone, and the torsion zone, were developed during the welding process, due to a combination of rotational, horizontal, and vertical motions of the plasticized metal. Figure 2 clearly illustrates the distinct plastic flow of the metal around the rotation axis with a threaded pin tool. Due to the friction of the shoulder, the metal underneath it first moves towards the pin tool (motion 1) and then moves downwards along the pin surface (motion 2). After the metal arrives at the pin tip, it is forced outwards and moves back following a helical rotational path (motion 3), as indicated via the arrows in Figure 2. With the repetition of the three motions above, onion rings structures (stir zone) are shaped in the joint. Colligan [24], Gerlich et al. [25], Guerra et al. [26], and Su et al. [27] also reported similar metal flow and intermixing during friction stir welding process. However, metal flow is significantly influenced by the geometrical shape of the pin. In case of cylindrical pin tool without screw, the metal around pin undergoes simple extrusion, and there seems to be no downward movement along the pin surface. Thus, this type of pin tool yields less stirring action, which induces insufficient deformation of material and production of void in stir zone [28]. Zhang et al. reported that the pin with flats acted as the cutting edge of a cutter, promoting more effective mixing. During the FSW process, the metal is trapped in the flats and then released behind, which strongly increases the flow of metal between the probe and matrix [20].

Friction stir welding achieves solid phase bonding not only by producing severe plastic deformation but also by locally introducing frictional heat [29], and the metal flow mechanism and thermal mechanism of FSW process are strongly coupled. Heat occurs because of friction between shoulder and top surface of the sheets and, to a lesser extent, at the pin surface, which induces the softening of butt material. Finally, metallurgical bonding is formed between the separated sheets. In order to obtain sufficient frictional heat, the angle of the tool is fixed at a certain small angle. It is difficult to accurately measure temperature of FSWed welds, therefore many finite element (FE) 
models have been established to compute temperature distribution through plastic dissipation and friction phenomena during FSW process [30,31]. A moving heat source associated with the friction between rotational shoulder and the work-piece is used to consider transfer heat [32]. It indicates that the maximum temperature near welds is related to the tool holding time, rotational speed, and tool transverse speed. Ulysse modeled the stir-welding process using three-dimensional visco-plastic modeling, which indicated the variation of the stir-welding temperatures as a function of welding speed [33]. In addition, Heurtier et al. [34] systematically described the thermal modeling of friction stir welding, indicating that the heat production of FSW process mainly came from two sources-the plastic strain and the friction of the shoulder on the surface of the work-pieces (neglecting the effect of the friction of the pin). Based on a few hypotheses, the average power $q$ is obtained as following equation [34]:

$$
q=\frac{2 \pi}{3} \mu p \omega R_{S}^{3}
$$

where $\mu$ is the local coefficient of friction, $p$ is the normal pressure, $\omega$ is the angular velocity, and $R_{\mathrm{S}}$ is the tool shoulder radius. It is well known that suitable heat input leads to the formation of fine, dynamically recrystallized grains in stir zones [35,36], while too high a temperature causes grain coarsening. Thus, by evaluating temperature value of FSW, this value can be well controlled at the level a little above the dynamically recrystallized temperature.

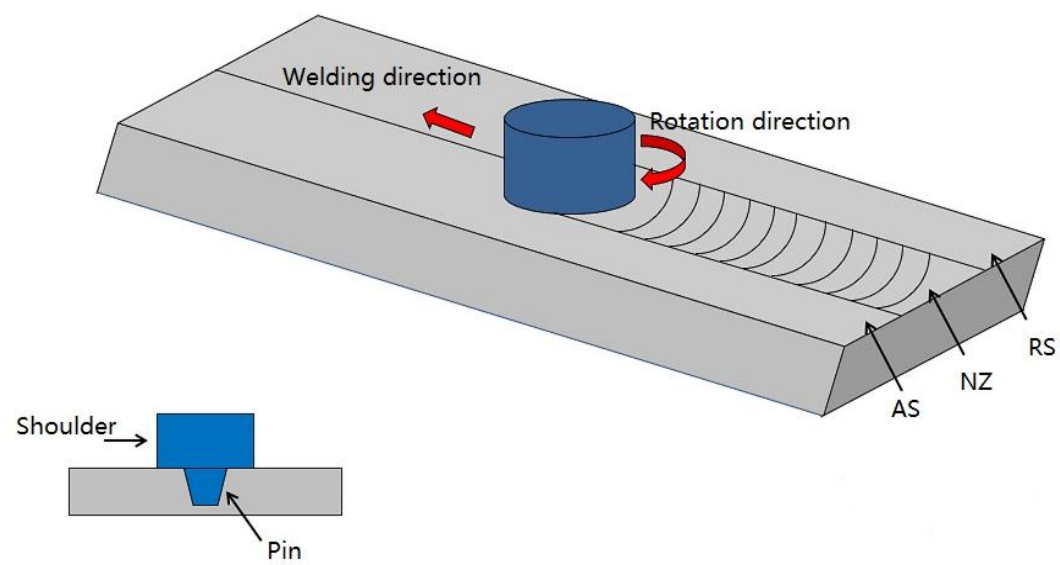

Figure 1. Schematic illustration of friction stir welding (FSW) (AS: Advancing Side; NZ: Nugget Zone; RS: Retreating Side).

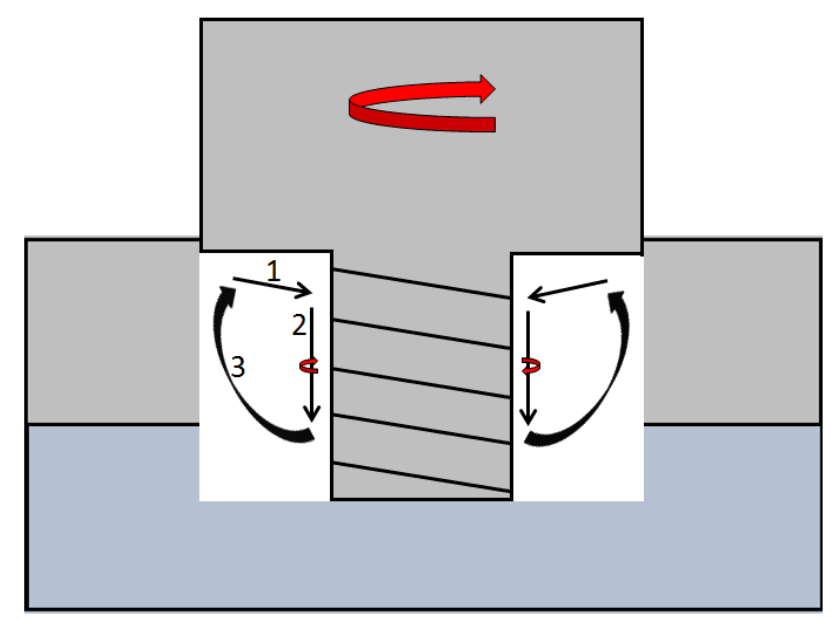

Figure 2. Schematic illustration of material flow during FSW. 


\section{Macro-Defects of Friction Stir Welded (FSWed) Magnesium Alloys}

During the FSW process, several macro-defects like porosity, hot cracks, voids, and tunnels, etc., are possibly generated due to insufficient material flow or excess heat input mainly influenced by rotational speed $(\omega)$ and travel speed $(v)$ [28,37-43]. We have discussed that higher tool rotational speeds generate larger heat, which results in more thermal stress during cooling process, while lower tool rotational speeds lead to insufficient material flow due to the fact that the frictional heat is not sufficient to promote joint material flow. Thus, joints without defects are only formed at optimum rotational speeds. In case of the effect of welding speed, the defects are caused by too high or too slow welding speed. Kim et al. [42] reported that excess heat input caused by the smaller travel speed lead to a larger mass. However, increasing welding speed, the top part material is pumped downward into the weld nugget zone, which results in sufficient material flow around the rotational axis. In addition, higher axial force can increase the friction force between lower surface of shoulder and top surface of sheets, which may cause excess heat input and thinner thickness [28]. In the case that the axial force is relatively low, there is the possibility of insufficient stirring at the bottom of the stir zone. Thus, according to the experimental data, the axial force of $3-5 \mathrm{kN}$ is optimized for gaining a promising welding joint.

Figure 3 summarizes the relationship between defects and different welding conditions $(V, W)$ with other parameters held constants [37,39-41,43-47]. There should be a good FSW condition (condition I) where the appropriate welding speed and rotational speed leading to a promising joint without defects. In the case of condition II (with lower welding speed and higher rotational speed), excess heat input results in large amount of defects in the joint. As for the insufficient heat input in condition III, severe defects (inner voids all along the weld) are formed at higher welding speed and lower rotational speed. There is an interesting phenomenon that the joints without defects are possibly obtained in Condition IV (high rotational speed and welding speed), which has been discussed by Xin et al. in their study [43]. Such conditions can provide appropriate heat input, in which the welding is characterized by relatively high stability of the tool load, thus presumably reflecting a more stable character of material flow. From the aforementioned results, it can be found that defects of FSWed welds are generated by improper temperature, and the peak temperature can be estimated by Equation (2) [48]:

$$
\frac{T}{T_{\mathrm{m}}}=K\left(\frac{W^{2}}{V \times 10^{4}}\right)^{\alpha}
$$

where $T_{\mathrm{m}}$ is the alloy's melting point, $W$ is rotational speed, $V$ is welding speed, $\alpha$ and $K$ are the constants. Using this relationships for $\mathrm{Mg}$ alloy, the proper heat input can be obtained in condition I or IV by adjusting the $W / V$ ratio.

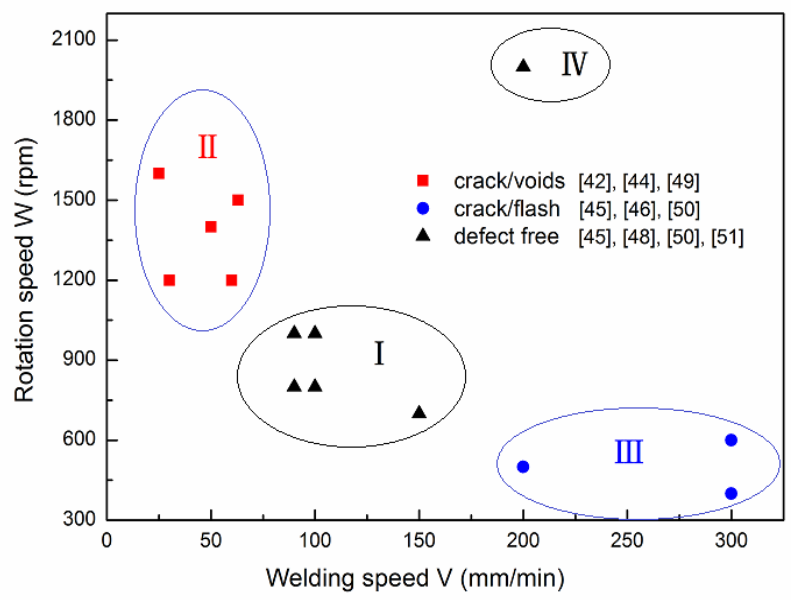

Figure 3. Relationship between the macro-defects and the welding parameters. 
A welding procedure with optimal parameters generates the required heat input and suitable material flow leading to the joint without macro-defects. Amount of previous literatures confirm that various series of $\mathrm{Mg}$ alloys can be successfully bonded with a relatively wide range of welding parameters. However, the joints without defects obtained at different parameters may cause different microstructure and properties, which will be discussed in detail in the next section.

\section{Macrostructure of FSW Joints}

In terms of the distinct thermo-mechanical histories during the welding process, a unique Onion Ring can be frequently identified in the friction stir joint $[16,36,48]$, as schematized in Figure 4 . From the center to the edge, the welding joint shows four regions, i.e., nugget zone (NZ), thermo-mechanically affected zone (TMAZ), heat-affected zone (HAZ), and base metal (BM). Those zones with various features mainly result from different material flow. The HAZ is characterized by undeformed grains and presents some grain coarsening (only due to the influence of heat). Thus, structure features of HAZ and BM are broadly similar to each other. TMAZ experiences higher thermal histories and mild material flow; as a result, there are elongated grains in TMAZ. In addition, the features of TMAZ in AS and RS are asymmetrical due to more severe material flow on the AS. Moreover, banded structures are observed in the interface between TMAZ and NZ, and they are clearly revealed in AS, while they are is not pronounced in RS. In case of NZ (under the tool), a number of fine grains are obtained, and the bottom is of finer grains than top zone. It is generally accepted that those equiaxed fine grains are generated by recrystallization.

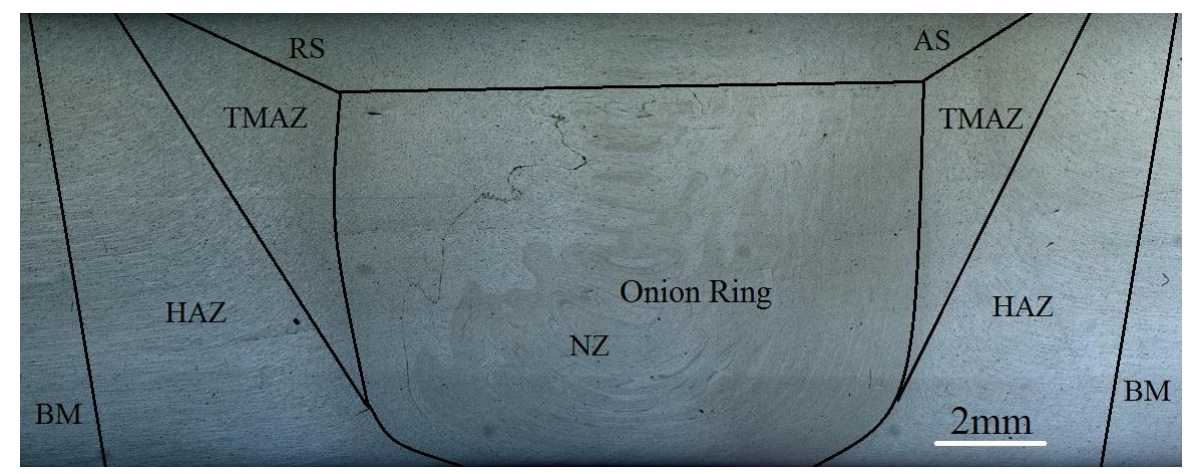

Figure 4. Macro-structure of FSWed joint (TMAZ: thermo-mechanically affected zone; HAZ: heat-affected zone; BM: base metal).

\section{Microstructure of FSW Joints}

Attempting to provide deeper insight into the microstructure development of FSW joints, the distribution of grain size, texture evolution, and grain development will be summarized in this section in detail.

\subsection{Distribution of Grain Size}

It is accepted that the recrystallization and geometry during deformation lead to grain refinement in FSWed welds [40,41,43,48-52]. The heat input of geometry deformation is different in different zones of FSWed welds, which causes a different distribution of grain size. The HAZ with a distance far away from the stirring tool has the characteristics of slightly coarser grains than those of the BM. It is very possible that the material in this zone undergoes no plastic deformation but only heating exposure, which induces grains growth. However, grain refining in the TMAZ mainly results from influence of shoulder friction. Thus, there are partially, recrystallized refined grains and a few elongated grains along direction of stirring action, following a grain-size gradient. This extraordinary microstructure in the TMAZ is mainly due to insufficient heating temperature or strain of dynamic recrystallization 
during FSW [52]. In addition, the grain size in AS is a bit coarser than that in RS. It results from the greater strain in AS [40]. In the case of the stir zone, the metals undergo extreme levels of plastic deformation and thermal exposure (at elevated temperature), which normally leads to significant grain refinement. As a result, the microstructure consists almost entirely of dynamically recrystallized grains and the grain size is homogeneously centered on a smaller value. The specific character of SZ (stir zone) may be explained in terms of the dynamic recrystallization during severe plastic deformation of FSW. A high rate of the high-angle grain boundaries (HAGBs) (about 97.5) after FSW was observed in cast Mg-Al-Zn [53], which indicates that dynamic recrystallization occurred in SZ. Moreover, some investigations showed that dynamic recrystallization gives rise to low-angle grain boundaries (LAGBs) and high-angle grain boundaries (HAGBs) $[48,54]$. However, of particular interest is the observation that the grains in SZ grow up after FSW in some cases. This is attributed to the ultrafine, grained microstructure of the base material, which is unstable in the thermal cycle during FSW. The heat input generated by plastic deformation provides the driving force for recovery, which will lead to grain growth in SZ [55]. Su et al. have pointed out the fact that the evolution of the grain structure in SZ may be associated with grain boundary structure, grain size, and dislocation density of the initial microstructure of the base material [56]. Ultrafine grained material, with a large quantity of dislocations and high-angle boundaries, easily causes the growth of grains during friction stir welding process. This phenomenon may be explained by the recovery, which leads to the growth of grain by consuming defect density within the grains [57]. Moreover, the grain size is also affected by the initial hardness, as was discussed by Chang et al. [58]. The material with lower hardness leads to lower heat input.

\subsection{Texture Distribution}

It is well known that the very specific character of metal flow during FSW extremely likely creates an inhomogeneous distribution of crystallographic texture in welds. In addition, due to the limited number of available slip systems associated with hexagonal close-packed crystal structure, magnesium alloys are very sensitive to crystallographic texture. As a result, a large number of studies have revealed that strong local texture produced during FSW significantly influences the microstructure $[3,41,43,46,59,60]$. Moreover, the distribution of texture obviously changes from base material to stir zone associated with the non-uniform plastic deformation in different zone. Plastic deformation of magnesium alloys is mainly attributed to slip deformation on the (0001) basal plane, with the lowest critical resolved shear stress at room temperature. A large number of researchers have pointed out that the complicated texture is also related to shear stress introduced by stirring tool [61-63].

In the case of magnesium, the base material has no obvious texture or a moderate texture, with the $c$-axis of (0001) plane nearly parallel to ND (normal direction). After FSW, a strong fiber texture with the basal $\{0001\}$ planes is formed in SZ, with the direction (basal (0001) planes) approximately perpendicular to the welding direction. A number of studies have demonstrated that the formation of this type of fiber texture (so-called B-fiber $(0002)<\mathrm{uvtw}>$ ideal simple shear texture) has contributed to the simple shear stress introduced by the rotating shoulder or pin $[48,54,59]$. Many researchers summarize the complicated orientation distribution in different zones of FSW joint (shown in Figure 4). With the position moving from the interface (between TMAZ and SZ) to SZ along mid-thickness of the welds, the $c$-axis of most grains tilt from TD to WD (welding direction) $[44,50,59,60]$, and the initial texture (introduced by rolling) decreases in strength, and a new texture with direction of $<0001>$ nearly parallel to WD appears. The formation of the strong $<0001>\|$ WD texture in welds is due to the simple shear deformation produced by the rotating pin. Suhuddin and Park reported that metal in the SZ sharply interacts with the pin, resulting in the corresponding alignment of the (0002) basal planes with the pin column surface (the basal plane (0002) for the SZ has a larger maximum relative pole intensity than that of the basal material $[54,61])$. 
Of particular interest is the observation that (0001) pole figures obtained from the different locations along the centerline of SZ are perpendicular to the TD, as illustrated in Figure 5. The joint is divided into three parts, i.e., the top, middle (with the similar texture discussed in the above paragraph), and bottom zone. The top zone displays a strong texture with $c$-axis of most grains nearly parallel to the ND (alignment of (0001) basal planes with the lower surface of the shoulder), which is attributed to the compression introduced by the shoulder. In the bottom zone (not shown in Figure 5), due to the influence of constrained shoulder and back plate, an extremely strong texture occurs. Chen et al. investigated the distribution of texture in FSWed joints; they found that the reorientation of $<0001>$ changes from WD to ND in bottom zone (relatively low temperature) [55]. It had been demonstrated by Yu et al. [64] that the $<0001>\| W D$ component tends to reorient to the near-ND due to the twinning that occurs prior to recrystallization. However, the investigation of the texture distribution in the bottom region is still limited up to now.

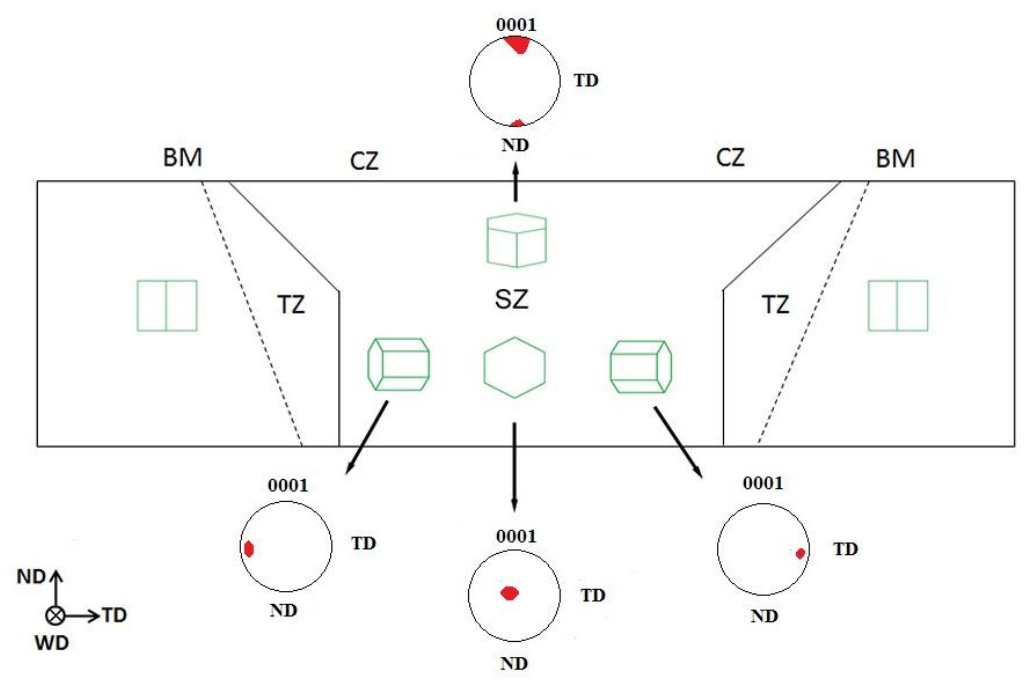

Figure 5. Texture distribution of the various regions of FSW joint (TZ: transition zone; SZ: stir zone; CZ: crown zone; TD: transverse direction; ND: normal direction; WD: welding direction).

\subsection{Grain Structure Development during FSW}

In order to provide more in-depth insight into the microstructure development during FSW, using such techniques as grain refinement and texture evolution, the "stop-action technique" proposed by Prangnell and Heason [65] was used to reveal the mechanisms of microstructural evolution during FSW of the magnesium alloys.

The grain structure evolution is different in different stages [54]. Far ahead of the tool, pronounced wedge- or lens-shaped $\{10 \overline{1} 2\}$ twining was observed inside the grains (Figure 6a), and the twins typically have an orientation close to $<0001>\| W D$. Thus, this indicates that the grain refining and the texture in this zone are attributable to appearance of the twinning. When approaching the tool, the geometrical effects of strain mainly affect the structural development, and the refinement process is associated with the original boundary and twinning [66]. Mironov et al. investigated the microstructural evolution in ZK60A magnesium alloy. They found that grain refinement preferentially occurred around original grain boundaries, which resulted in the appearance of the "mixed structure" (coarse bands and small equiaxed grains). Furthermore the structural characters of discontinuous and continuous recrystallization were observed in NZ. This phenomenon indicated that this process may be related to discontinuous and continuous recrystallization. Therefore, although nearly no twins are observed in the welds after FSW, it should be emphasized that twinning plays an important role on microstructural evolution of FSW joint, which is also demonstrated by other studies $[67,68]$. Due to the insufficiency of the basal slip to accommodate arbitrary strains in magnesium, twinning 
promotes material deformation [48]. In addition, Yu et al. pointed out that the texture component (approximate $40^{\circ}$ off the ND towards the WD) that appeared in SZ resulted from easier activation of the twinning mode [64]. Therefore, it is very possible that the activation of twins led to texture clustering (as discussed in Section 5.2). Moreover, due to severe plastic deformation, twins lose their original morphology and then transform into irregular equiaxed grains (random HAGBs) by absorbing dislocations in the position close to the SZ (Figure $6 \mathrm{~b}$ ), which also reveals that twins promote grain refinement. In addition, serrated grain boundaries were also observed in Figure $6 \mathrm{~b}$; as well as an extensive formation of "new" grains and gradual transformation into high angle boundaries, which also indicates that the continuous recrystallization process is activated. Previous studies have reported that grain boundaries of original grains and twins appear wavy, and several bulges are present along the grain boundaries. This indicates that the initial stage of discontinuous recrystallization associating with twinning is triggered $[54,69,70]$. As discussed above, discontinuous recrystallization occurs in the positions with relatively high deformation stress; however, there also exists grains refinement associated with continuous recrystallization. According to studies about misorientation distribution in literature $[48,54,65]$, a process developed by gradual shifting of the low-angle boundaries to high-angle boundaries is observed in the SZ. Moreover, the fraction of $10-15^{\circ}$ boundaries significantly increases with the disappearance of the misorientation in the range of $30-85^{\circ}$. The special character of this misorientation change may be explained in terms of the continuous re-crystallization and grain-convergence associating with B-fiber texture.
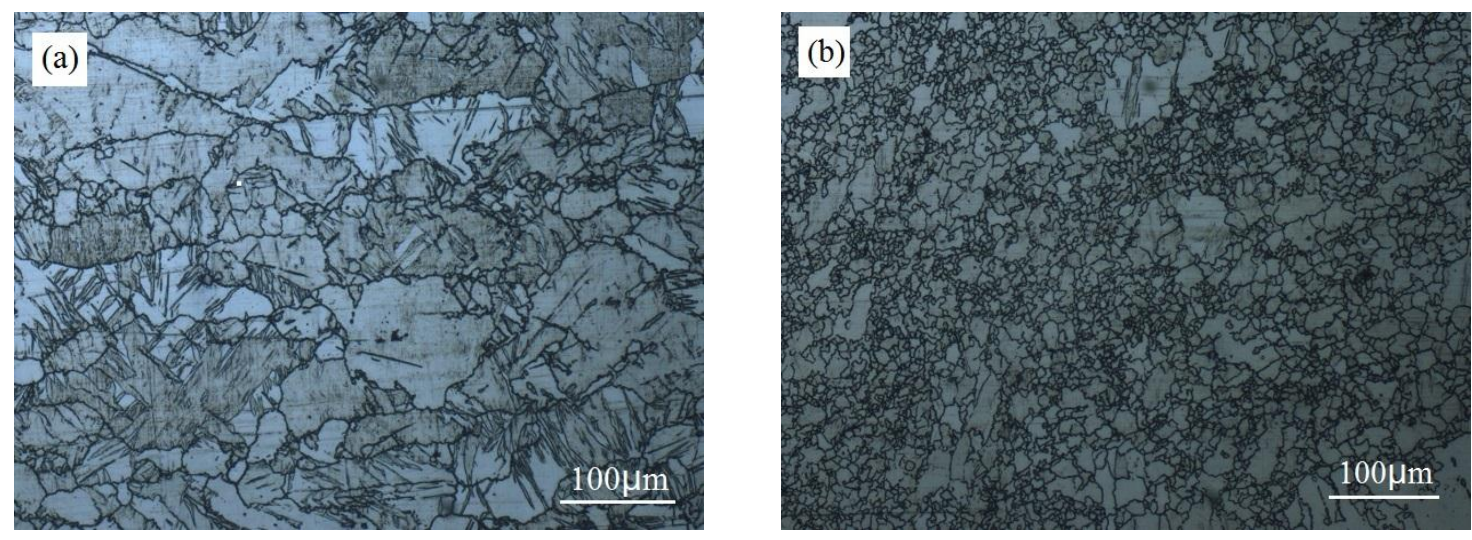

Figure 6. Microstructure evolution of different locations ahead the tool keyhole: (a) the region next to the base material; (b) the region next to the stirring pin.

In summary, microstructural evolution of FSW joint is a complex process driven by twinning, discontinuous recrystallization, continuous recrystallization, and grain-convergence. However, it should be emphasized that it remains unclear which mechanism is predominant in the interaction between different grain refining mechanisms during this process. More detailed studies are needed to reveal this issue.

\section{Mechanical Properties of FSW Joint}

\subsection{Microhardness}

The micro-hardness is inhomogeneously distributed in FSW welds, which is related to the grain size, crystallographic texture, dislocation density, and distribution of hardening phases. The Hall-Petch parameter is utilized in revealing relationship between hardness $\left(H_{\mathrm{V}}\right)$ and grain size (d) by Chang et al. [58]. The hardness can be expressed as follows (Equation (3)):

$$
H_{\mathrm{V}}=40+72 d^{-\frac{1}{2}}
$$


It shows that the hardness value increases with the reduction of grain size. That is to say, for the magnesium alloys AZ31 and AZ61 with less eutectic phases, the hardness of FSW welds is associated with grain size in different zone. Some studies have demonstrated the effect of grain size on the mechanical properties of FSW welds [41,51,52,55], in which more refined grains obtained in SZ lead to an increase of hardness. However, Salih et al. found that the micro-hardness in the nuggets (with the lowest grain size) is lower than that in base material [17], which is in disagreement with the Hall-Petch relationship. It is very possible that distribution of hardening phases exerts a significant influence on the micro-hardness. This result was confirmed in a later study by Kouadri-Henni and Barrallier [40]. In case of as-cast AZ91 (solid-solution hardened magnesium alloy), a large number of eutectic phases $\left(\alpha-\mathrm{Mg}+\beta-\mathrm{Mg}_{17} \mathrm{Al}_{12}\right)$ in SZ are dissoluted, and a majority of $\beta-\mathrm{Mg}_{17} \mathrm{Al}_{12}$ phases are dissolved into the $\alpha-\mathrm{Mg}$ matrix due to the thermal cycle and mechanical stirring, which indirectly decrease the micro-hardness in SZ. Compared to the effect of grain size and hardening phases, crystallographic texture and dislocation density have relatively less effect on the hardness of FSW welds; it also possible that more studies are focused on the former. Another interesting point is the observation that hardness exists as a sharp change in the edge of the pin $[17,41,55]$, which may result from many factors. However, it is still unknown which factor plays a predominant role in this zone.

\subsection{Tensile Properties}

After FSW, the yield strength, ultimate tensile strength, and elongation of the joints decrease to different extent compared to the original material. A large number of researchers stated that strong micro-texture introduced by FSW plays a dominant role in the variation in tensile properties $[3,43,51,52,55,59,60,71,72]$. Xin et al. reported that fracture occurs on interface between TMAZ and SZ of the AS, and the yield strength of the joint was largely reduced compared to that of the basal material (from 123 to $73 \mathrm{MPa}$ ) [43]. It may be attributed to the corresponding texture transition in this fracture interface. Park et al. discussed that the (0001) plane is roughly perpendicular to the WD in NZ, while most grains in TMAZ have the (0001) plane perpendicular to the TD. Thus, there may be a zone with the (0001) plane of grains lying at $45^{\circ}$ to the TD. It is very possible that the maximum resolved shear stress on (0001) basal planes of the grains is obtained in the particular interface above, which results in a significant reduction in the tensile properties and fracture in this zone [52]. In addition, Liu et al. [59] reported that the cracks may originate from the triple junction region of TMAZ, SZ, and CZ, which is due to the complicated extension twinning associating with textural variation. It also demonstrated that drastic textural variation induces the inhomogeneous twinning pattern, which leads to the fracture in this zone. In order to clarify the formation mechanism of the crack, Mironov and his colleagues systematically described the development of the crack in FSW weld during the tensile test [3]. Their studies showed that the cracks were favored at the bottom surface of the stir zone, and the final crack path was changed towards AS, which is attributed to the activity of double $\{10 \overline{1} 1\}-\{10 \overline{1} 2\}$ twinning associating with the particular texture as well as the relatively high strain accumulation, respectively.

The yield strength is also related to the grain size [43,71], and this relationship can be estimated by Equation (4):

$$
\sigma_{\mathrm{y}}=\sigma_{0}+k d^{-\frac{1}{2}}
$$

where $\sigma_{\mathrm{y}}$ is the yield strength of material, $d$ is the grain size, $\sigma_{0}$ is the friction stress, and $k$ is a constant. It indicates that yield strength of FSWed joint increases with the decreasing of the grain size. Chen and Fujii investigated the effect of grain size on the mechanical properties of FSWed weld [41]. The yield strength and ultimate tensile strength of the fine-grained joints are higher than those of the coarse-grained joints. This result was confirmed in a later study by Pan et al. [51]. They found that the joint with low average grain size of $5.2 \mu \mathrm{m}$ is of a higher yield strength than the joint with large average grain size of $8.3 \mu \mathrm{m}$. 
Besides crystallographic texture and grain size, dislocation density also strongly influences the tensile properties. The following strain hardening model takes into account the effects of grain size and dislocation [73]:

$$
\begin{gathered}
\sigma=\sigma_{0}+\sigma_{\mathrm{HP}}+\sigma_{\mathrm{d}} \\
\sigma_{\mathrm{HP}}=k d^{-\frac{1}{2}} \\
\sigma_{\mathrm{d}}=M \alpha G b \rho^{-\frac{1}{2}}
\end{gathered}
$$

where $\sigma_{0}$ is the frictional contribution, $\sigma_{\mathrm{HP}}$ is Hall-Petch contribution, $\sigma_{\mathrm{d}}$ is Taylor dislocation contribution, $\rho$ is the dislocation density, $\alpha$ is a constant, $M$ is the Taylor factor, $G$ is the shear modulus, and $b$ is the Burgers vector. It is well known that the plastic deformation is related to the slip and twinning in magnesium alloys, and the slip is associated with the dislocation motion. Humphreys reported that, due to recrystallization, the zone in FSW weld with refined grains has a greater total grain boundary area, which may impede the dislocation motion [74].

\section{Conclusions and Future Challenges}

Comparing traditional welding and FSW to weld magnesium alloys highlights the pronounced microstructure and superior mechanical properties of the welds of FSW. By means of adopting appropriate process parameters, the required heat input is attained. Increasing the rotational speed or reducing the welding speed optimally can result in higher heat input and thus promote suitable material mixing. Most of the studies are focused on the optimization of process parameters and evaluation of microstructure evolution of Al-Mg series magnesium alloys. The maturity of adopting FSW to joint magnesium alloys is still at an early stage in industrial application.

Widespread applications of FSW of magnesium alloys are still limited due to a key issue: the significant reduction of tensile properties at the interface between TMAZ and SZ. Early research indicated that the decrease in strength is associated with many factors. Thus, there is a clear need for more effort to understand the dominant effect causing the decreasing strength. Furthermore, there is no general means to enhance the strength of the joints. Thus, further systematic studies need to be carried out to deal with the drawback of low strength. For instance, some literature has shown that the addition of a metallic foil interlayer between the welded sheets markedly improves the mechanical properties. To the authors' knowledge, studies of the addition of metallic foil are limited and few researchers are focused on adjusting the IMCs formation by adding external foil materials. Further work needs to be carried out to define the welding parameters and the types of metallic foil used for various magnesium alloy joints.

Furthermore, outstanding FSWed joints are obtained by means of the appropriate flow of plasticized metal, which is associated with tool rotation speed, traverse speed, and axial pressure. The microstructure evolution and mechanical properties of magnesium alloys bonded by FSW are largely dependent on the flow of metal in the joints. However, there are limited data on the relationship between welding parameters and the flow of metal. More effort is needed to obtain the pronounced joints of magnesium alloys by inhibiting the inappropriate flow of metal.

Finally, it should be emphasized that present studies have provided an insight into the characterization of the final microstructure in the stir zone. However, relatively little attention has been paid to how the microstructure actually develops and which mechanism governs the microstructural evolution during the FSW of different types of magnesium alloys. Thus, combined with the "stop-action" technique, more efforts are needed to fill this important technical gap.

Acknowledgments: This work was financially supported by the National Natural Science Foundation of China (No. 51275332), the Natural Science Foundation of Shanxi Province (No. 201601D011036) and Natural Science youth Foundation of Shanxi Province (No. 2015021130).

Author Contributions: Yajie Li and Zhisheng Wu conceived and designed the experiments; Yajie Li performed the experiments; Fengming Qin and Yajie Li analyzed the data; Cuirong Liu contributed reagents/materials/analysis tools; Yajie Li wrote the paper. 
Conflicts of Interest: The authors declare no conflict of interest.

\section{References}

1. Patel, V.K.; Bhole, S.D.; Chen, D.L. Influence of ultrasonic spot welding on microstructure in a magnesium alloy. Scr. Mater. 2011, 65, 911-914. [CrossRef]

2. Sahu, P.K.; Pal, S. Influence of metallic foil alloying by FSW process on mechanical properties and metallurgical characterization of AM20 Mg alloy. Mater. Sci. Eng. A 2017, 684, 442-455. [CrossRef]

3. Mironov, S.; Onum, T.; Sato, Y.S.; Yoneyama, S.; Kokawa, H. Tensile behavior of friction-stir welded AZ31 magnesium alloy. Mater. Sci. Eng. A 2017, 679, 272-281. [CrossRef]

4. Dong, H.G.; Liao, C.Q.; Yang, L.Q. Microstructure and mechanical properties of AZ31B magnesium alloy gas metal arc weld. Trans. Nonferrous Met. Soc. China 2012, 22, 1336-1341. [CrossRef]

5. Xiao, L.; Liu, L.; Chen, D.L.; Esmaeili, S. Resistance spot weld fatigue behavior and dislocation substructures in two different heats of AZ31 magnesium alloy. Mater. Sci. Eng. A 2011, 529, 81-87. [CrossRef]

6. Chi, C.T.; Chao, C.G.; Liu, T.F.; Wang, C.C. Relational analysis between parameters and defects for electron beam welding of AZ-series magnesium alloys. Vacuum 2008, 82, 1177-1182. [CrossRef]

7. Wang, A.H.; Xu, H.G.; Yang, P. Nd:YAG laser butt welding of a 12 vol. \% SiC particulate-reinforced magnesium alloy composite. Mater. Lett. 2007, 61, 4023-4026. [CrossRef]

8. Yu, S.Y.; Chen, X.J.; Huang, Z.Q.; Liu, Y.H. Microstructure and mechanical properties of friction stir welding of AZ31B magnesium alloy added with cerium. J. Rare Earths 2010, 28, 317-320. [CrossRef]

9. Ma, Z.Y.; Pilchak, A.L.; Juhas, M.C.; Williams, J.C. Microstructural refinement and property enhancement of cast light alloys via friction stir processing. Scr. Mater. 2008, 58, 361-366. [CrossRef]

10. Feng, A.H.; Xiao, B.L.; Maz, Y.; Chen, R.S. Effect of friction stir processing procedures on microstructure and mechanical properties of Mg-Al-Zn casting. Metall. Mater. Trans. A 2009, 40, 2447-2456. [CrossRef]

11. Maz, Y. Friction stir processing technology: A review. Metall. Mater. Trans. A 2009, 39, 642-658.

12. Afrin, N.; Chen, D.L.; Cao, X.; Jahazi, M. Microstructure and tensile properties of friction stir welded AZ31B magnesium alloy. Mater. Sci. Eng. A 2008, 472, 179-186.

13. Chowdhury, S.M.; Chen, D.L.; Bhole, S.D.; Cao, X. Tensile properties and strain-hardening behavior of double-sided arc welded and friction stir welded AZ31B magnesium alloy. Mater. Sci. Eng. A 2010, 527, 2951-2961. [CrossRef]

14. Chowdhury, S.H.; Chen, D.L.; Bhole, S.D.; Cao, X.; Wanjara, P. Friction stir welded AZ31 magnesium alloy: Microstructure, texture, and tensile properties. Metall. Mater. Trans. A 2013, 44, 323-336. [CrossRef]

15. Liu, D.J.; Xin, R.L.; Zhao, L.Z. Effect of textural variation and twinning activity on fracture behavior of friction stir welded AZ31 Mg alloy in bending tests. J. Alloys Compd. 2017, 693, 808-815. [CrossRef]

16. Avettand-Fènoël, M.N.; Simar, A. A review about friction stir welding of metal matrix composites. Mater. Charact. 2016, 120, 1-17. [CrossRef]

17. Salih, O.S.; Ou, H.; Sun, W.; McCartney, D.G. A review of friction stir welding of aluminium matrix composites. Mater. Des. 2015, 86, 61-71. [CrossRef]

18. Thomas, W.M.; Staines, D.G.; Norris, I.M. Friction stir welding tools and developments. Weld. World 2003, 47, 10-17. [CrossRef]

19. Rai, R.; De, A.; Bhadeshia, H.K.D.H.; Debroy, T. Review: Friction stir welding tools. Sci. Technol. Weld. Join. 2011, 16, 325-342. [CrossRef]

20. Zhang, Y.N.; Cao, X.; Larose, S.; Wanjara, P. Review of tools for friction stir welding and processing. Can. Metall. Q. 2012, 51, 250-261. [CrossRef]

21. Padmanaban, G.; Balasubramanian, V. An experimental investigation on friction stir welding of $A Z_{31} B$ magnesium alloy. Int. J. Adv. Manuf. Technol. 2010, 49, 111-121. [CrossRef]

22. Nandan, R.; DebRoy, T.; Bhadeshia, H.K.D.H. Recent advances in friction-stir welding process, weldment structure and properties. Prog. Mater. Sci. 2008, 53, 980-1023. [CrossRef]

23. Yang, Q.; Mironov, S.; Sato, Y.S.; Okamoto, K. Material flow during friction stir spot welding. Mater. Sci. Eng. A 2010, 527, 4389-4398. [CrossRef]

24. Colligan, K. Material flow behavior during friction stir welding of aluminum. Weld. Res. 1999, 172, $229-237$.

25. Gerlich, A.; Su, P.; Yamamoto, M.; North, T.H. Material flow and intermixing during dissimilar friction stir welding. Sci. Technol. Weld. Join. 2008, 13, 254-264. [CrossRef] 
26. Guerra, M.; Schmidt, C.; McClure, J.C.; Murr, L.E.; Nunes, A.C. Flow patterns during friction stir welding. Mater. Charact. 2003, 49, 95-101. [CrossRef]

27. Su, P.; Gerlich, A.; North, T.H.; Bendzsak, G.J. Intermixing in dissimilar friction stir spot welds. Metall. Mater. Trans. A 2007, 38, 584-595. [CrossRef]

28. Rajakumar, S.; Razalrose, A.; Balasubramanian, V. Friction stir welding of AZ61A magnesium alloy. Int. J. Adv. Manuf. Technol. 2013, 68, 277-292. [CrossRef]

29. Lee, W.B.; Yeon, Y.M.; Jung, S.B. Mechanical properties related to microstructural variation of $6061 \mathrm{Al}$ alloy joints by friction stir welding. Mater. Trans. 2004, 45, 1700-1705. [CrossRef]

30. He, X.; Gu, F.; Ball, A. A review of numerical analysis of friction stir welding. Prog. Mater. Sci. 2014, 65, 1-66. [CrossRef]

31. Dialami, N.; Chiumenti, M.; Cervera, M.; Agelet de Saracibar, C. Challenges in thermo-mechanical analysis of friction stir welding processes. Arch Comput. Methods Eng. 2017, 24, 189-225. [CrossRef]

32. Kıral, B.G.; Tabanoğlu, M.; Serindağ, H.T. Finite element modeling of friction stir welding in aluminum alloys joint. Math. Comput. Appl. 2013, 18, 122-131. [CrossRef]

33. Ulysse, P. Three-dimensional modeling of the friction stir-welding process. Int. J. Mach. Tools Manuf. 2002, 42, 1549-1557. [CrossRef]

34. Heurtier, P.; Jones, M.J.; Desrayaud, C.; Driver, J.H.; Montheillet, F.; Allehaux, D. Mechanical and thermal modelling of friction stir welding. J. Mater. Process. Technol. 2006, 171, 348-357. [CrossRef]

35. Sato, Y.S.; Kokawa, H. Distribution of tensile property and microstructure in friction stir weld of 6063 aluminum. Metall. Mater. Trans. A 2000, 32, 3023-3031. [CrossRef]

36. Mahoney, M.W.; Rhodes, C.G.; Flintoff, J.G.; Bingel, W.H.; Spurling, R.A. Properties of friction-stir-welded 7075 T651 aluminum. Metall. Mater. Trans. A 1997, 29, 1955-1964. [CrossRef]

37. Suni, B.R.; Reddy, G.P.K.; Mounika, A.S.N.; Sree, P.N.; Pinneswari, P.R. Joining of AZ31 and AZ91 Mg alloys by friction stir welding. J. Magnes. Alloys 2015, 3, 330-334.

38. Jaiganesh, V.; Sevvel, P. Effect of process parameters on the microstructural characteristics and mechanical properties of AZ80AMg alloy during friction stir welding. Trans. Indian Inst. Metals 2015, 68, 99-104. [CrossRef]

39. Rose, A.R.; Manisekar, K.; Balasubramanian, V. Influences of welding speed on tensile properties of friction stir welded AZ61A magnesium alloy. J. Mater. Eng. Perform. 2012, 21, 257-265. [CrossRef]

40. Kouadri-Henni, A.; Barrallier, L. Mechanical properties, microstructure and crystallographic texture of magnesium AZ91-D alloy welded by friction stir welding (FSW). Metall. Mater. Trans. A 2014, 45, 4983-4996. [CrossRef]

41. Chen, J.; Fujii, H.; Sun, Y.F.; Morisada, Y.; Kondoh, K. Optimization of mechanical properties of fine-grained non-combustive magnesium alloy joint by asymmetrical double-sided friction stir welding. J. Mater. Process. Technol. 2017, 242, 117-125. [CrossRef]

42. Kim, Y.G.; Fujii, H.; Tsumura, T.; Komazaki, T.; Nakata, K. Three defect types in friction stir welding of aluminum die casting alloy. Mater. Sci. Eng. A 2006, 415, 250-254. [CrossRef]

43. Xin, R.L.; Liu, D.J.; Shu, X.G.; Li, B.; Yang, X.F.; Liu, Q. Influence of welding parameter on texture distribution and plastic deformation behavior of as-rolled AZ31 Mg alloys. J. Alloys Compd. 2016, 670, 64-71. [CrossRef]

44. Rouhi, S.; Ashjari, M.; Mostafapour, A. Experimental study on the effects of friction stir welding parameters on the quality and the mechanical properties of the AZ91 joints. Int. J. Eng. Dev. Res. 2015, 3, 234-239.

45. Yang, J.; Ni, D.R.; Wang, D.; Xiao, B.L.; Ma, Z.Y. Friction stir welding of as-extruded Mg-Al-Zn alloy with higher Al content. Mater. Charact. 2014, 96, 135-141. [CrossRef]

46. Cavaliere, P.; Marco, P.P.D. Superplastic behavior of friction stir processed AZ91 magnesium alloy produced by high pressure die cast. J. Mater. Process. Technol. 2007, 184, 77-83. [CrossRef]

47. Mironov, S.; Onuma, T.; Sato, Y.S.; Kokawa, H. Microstructure evolution during friction-stir welding of AZ31magnesium alloy. Acta Mater. 2015, 100, 301-312. [CrossRef]

48. Zhao, Y.; Wang, Q.Z.; He, X.D.; Huang, J.; Yan, K.; Dong, J. Microstructure and mechanical properties of friction stir-welded Mg-2Nd-0.3Zn-0.4Zr magnesium alloy. J. Mater. Eng. Perform. 2014, 23, 4136-4142. [CrossRef]

49. Chen, J.; Ueji, R.; Fujii, H. Double-sided friction-stir welding of magnesium alloy with concave-convex tools for texture control. Mater. Des. 2015, 76, 181-189. [CrossRef] 
50. Liu, D.J.; Xin, R.L.; Li, Z.Y.; Liu, Z.; Zheng, X.; Liu, Q. The activation of twinning and texture evolution during bending of friction stir welded magnesium alloys. Mater. Sci. Eng. A 2015, 646, 145-153. [CrossRef]

51. Pan, F.S.; Xu, A.L.; Deng, D.; Ye, J.H.; Jiang, X.Q.; Tang, A.T.; Ran, Y. Effects of friction stir welding on microstructure and mechanical properties of magnesium alloy Mg-5Al-3Sn. Mater. Des. 2016, 110, 266-274. [CrossRef]

52. Park, S.H.C.; Sato, Y.S.; Kokawa, H. Effect of micro-texture on fracture location in friction stir weld of $\mathrm{Mg}$ alloy AZ61 during tensile test. Scr. Mater. 2003, 49, 161-166. [CrossRef]

53. Feng, A.H.; Ma, Z.Y. Microstructure evolution of cast Mg-Al-Zn during friction stir processing and subsequent aging. Acta Mater. 2009, 57, 4248-4260. [CrossRef]

54. Suhuddin, U.F.H.R.; Mironov, S.; Sato, Y.S.; Kokawa, H.; Lee, C.W. Grain structure evolution during friction-stir welding of AZ31 magnesium alloy. Acta Mater. 2009, 57, 5406-5418. [CrossRef]

55. Chen, J.; Fujii, H.; Sun, Y.F.; Morisada, Y.; Kondoh, K. Effect of grain size on the microstructure and mechanical properties of friction stir welded non-combustive magnesium alloys. Mater. Sci. Eng. A 2012, 549, 176-184. [CrossRef]

56. Sun, Y.F.; Fujii, H.S.; Takada, Y.; Tsuji, N.; Nakata, K.; Nogi, K. Effect of initial grain size on the joint properties of friction stir welded aluminum. Mater. Sci. Eng. A 2009, 527, 317-321. [CrossRef]

57. Kwan, C.; Wang, Z.R. Microstructure evolution upon annealing of accumulative roll bonding (ARB) $1100 \mathrm{Al}$ sheet materials: Evolution of interface microstructures. J. Mater. Sci. 2008, 43, 5045-5051. [CrossRef]

58. Chang, C.I.; Lee, C.J.; Huang, J.C. Relationship between grain size and Zener-Holloman parameter during friction stir processing in AZ31 Mg alloys. Scr. Mater. 2004, 51, 509-514. [CrossRef]

59. Liu, Z.; Xin, R.L.; Liu, D.J.; Shu, X.G.; Liu, Q. Textural variation in triple junction region of friction stir welded $\mathrm{Mg}$ alloys and its influence on twinning and fracture. Mater. Sci. Eng. A 2016, 658, 185-191. [CrossRef]

60. Liu, D.J.; Xin, R.L.; Yu, H.N.; Liu, Z. Comparative examinations on the activity and variant selection of twinning during tension and compression of magnesium alloys. Mater. Sci. Eng. A 2016, 658, 229-237. [CrossRef]

61. Park, S.H.C.; Sato, Y.S.; Kokawa, H. Basal plane texture and flow pattern in friction stir weld of a magnesium alloy. Metall. Mater. Trans. A 2003, 34, 987-994. [CrossRef]

62. Shang, Q.; Ni, D.R.; Xue, P.; Xiao, B.L.; Ma, Z.Y. Evolution of local texture and its effect on mechanical properties and fracture behavior of friction stir welded joint of extruded Mg-3Al-1Zn alloy. Mater. Charact. 2017, 128, 14-22. [CrossRef]

63. Yang, J.; Wang, D.; Xiao, B.L.; Ni, D.R.; Ma, Z.Y. Effects of rotation rates on microstructure, mechanical properties, and fracture behavior of friction stir-welded (FSW) AZ31 magnesium alloy. Metall. Mater. Trans. A 2013, 44, 517-530. [CrossRef]

64. Yu, Z.Z.; Choo, H.; Feng, Z.L.; Vogel, S.C. Influence of thermo-mechanical parameters on texture and tensile behavior of friction stir processed Mg alloy. Scr. Mater. 2010, 63, 1112-1115. [CrossRef]

65. Prangnell, P.B.; Heason, C.P. Grain structure formation during friction stir welding observed by the stop action technique. Acta Mater. 2005, 53, 3179-3192. [CrossRef]

66. Mironov, S.; Motohashi, Y.; Kaibyshev, R.; Somekawa, H.; Mukai, T.; Tsuzaki, K. Development of fine-grained structure caused by friction stir welding process of a ZK60A magnesium alloy. Mater. Trans. 2009, 50, 610-617. [CrossRef]

67. Yuan, W.; Mishra, R.S.; Carlson, B.; Verma, R.; Mishra, R.K. Material flow and microstructural evolution during friction stir spot welding of AZ31 magnesium alloy. Mater. Sci. Eng. A 2012, 543, 200-209. [CrossRef]

68. Mironov, S.; Yang, Q.; Takahashi, H.; Takahashi, I. Specific character of material flow in near-surface layer during friction stir processing of AZ31 magnesium alloy. Metall. Mater. Trans. A 2010, 41, 1016-1024. [CrossRef]

69. Galiyev, A.; Kaibyshev, R.; Gottstein, G. Correlation of plastic deformation and dynamic recrystallization in magnesium alloy ZK60. Acta Mater. 2001, 49, 1199-1207. [CrossRef]

70. Beer, A.G.; Barnett, M.R. Correlation of plastic deformation and dynamic recrystallization in magnesium alloy ZK60. Metall. Mater. Trans. A 2007, 38, 1856-1867. [CrossRef]

71. Commin, L.; Dumont, M.; Masse, J.E.; Barrallier, L. Friction stir welding of AZ31 magnesium alloy rolled sheets: Influence of processing parameters. Acta Mater. 2009, 57, 326-334. [CrossRef] 
72. Woo, W.; Choo, H.; Brown, D.W.; Liaw, P.K.; Feng, Z. Texture variation and its influence on the tensile behavior of a friction-stir processed magnesium alloy. Scr. Mater. 2006, 54, 1859-1964. [CrossRef]

73. Afrin, N.; Chen, D.L.; Cao, X.; Jahazi, M. Strain hardening behavior of a friction stir welded magnesium alloy. Scr. Mater. 2007, 57, 1004-1007. [CrossRef]

74. Humphreys, F.J.; Hatherly, M. Recrystallization and Related Annealing Phenomena; Elsevier Ltd.: Oxford, UK, 2004.

(c) 2017 by the authors. Licensee MDPI, Basel, Switzerland. This article is an open access article distributed under the terms and conditions of the Creative Commons Attribution (CC BY) license (http://creativecommons.org/licenses/by/4.0/). 